if cleansed as usual and ignited in a small test tube gives a white sublimate indistinguishable macroscopically from arsenic tri-oxide, but under the microscope the sublimate does not show the characteristic octahedra and tetrahedra of arsenious acid. If the "Marsh" test be performed on a dilute solution of selenium (10 and 20 milligrammes of selenious acid were respectively used), as correctly stated by Dr. F. W. Tunnicliffe and Dr. Otto Rosenheim, ${ }^{1}$ no deposit occurs in the tube at the site where the arsenical nirror usually forms, and the selenium deposits in the flask as a dark reddish precipitate and inhibits the evolution of the hydrogen to some extent.

Now although selenium does not give any result per se with the "Marsh" test in the absence of arsenic, yet the astonishing fact was demonstrated that it has a most decided influence on the nature of the mirror if arsenic be also present.

Experiment 1.-If half a milligramme of arsenic trioxide be introduced into the flask with 10 milligrammes of selenious acid the resulting mirror is quite different in appearance from that obtained from the arsenic alone. Thus the proximal half of the mirror is of a vermilion red colour, while the distal portion has the usual appearance of the arsenical mirror; but much of the arsenic appears to be retained and the true arsenical portion of the mirror is only about a tenth of the size of that obtained from the same amount of arsenic with no selenium (vide Fig. 1).

Experiment 2.-A fresh experiment was performed with five milligrammes of selenious acid and half a milligramme of arsenic tri-oxide; the resulting mirror was of the same nature as the preceding, but the true arsenical portion was larger, being about one quarter the proper size, and the proximal portion was still of a vermilion red colour (vide Irig. 2).

Experiment 3.-A fresh experiment was performed with half a milligramme of arsenious acid and one milligramme of selenious acid in flask. Here the influence of the selenium was only slight. No red was detected in the proximal portion of the mirror, and the arsenical portion of the mirror was about from one-half to two-thirds as large as that

FIG. 1.

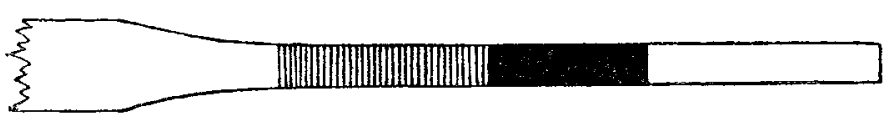

FIG. 2.

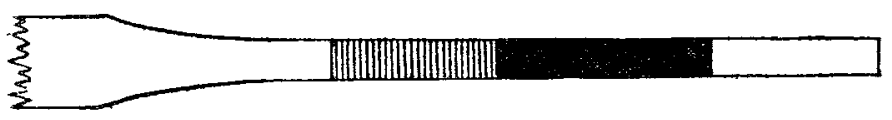

FrG. 3.

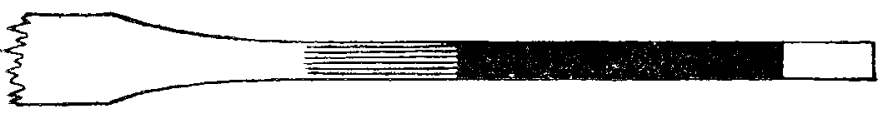

Fig. 4

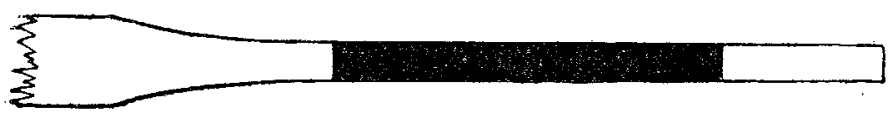

Fig. 1. Mirror from one-half milligramme of $\mathbf{A s}_{2} \mathrm{O}_{3}$ and ten milligrammes selenious acid. Fig. 2. Mirror from one-half milligramme $A$ ond acid 3 . 3 in acid. Fig. 3. Mirror from one-half milligramme $\mathrm{As}_{2} \mathrm{O}_{3}$ and one milligramme selentous acta. Fig. 4. Mirro from one-half milligramme $\mathrm{As}_{2} \mathrm{O}_{3}$ alone. The solid black cho the extent

horizontal shading the brown selenious portion.

obtained without any selenium present. Still, there was a definite difference observable between the mirror obtained with half a milligramme of arsenic tri-oxide and one milligramme of selenious acid and one from half a milligramme of arsenic tri-oxide alone. In the former case a proximal brown portion of about half an inch in length preceded the true arsenical mirror (vide Figs. 3 and 4).

The above results are of great interest, for they prove that

1 The Lancet, Feb. 2nd, 1901, p. 318. if it is granted, as has been suggested, that the recent beerpoisoning epidemic has been due to selenium and not arsenic, then certainly many instances must have occurred where the selenium had been found in amounts 20 or 10 times as great as the arsenic, as in Experiments 1 and 2 above, and if so, then most characteristic and peculiar mirrors would have been obtained by the "Marsh" test, applied, as it certainly has been applied, to many of the contaminated beers and sugars.

Now it has been my privilege to examine many of the samples of contaminated beer from Manchester and the district round, and from all these samples by the "Reinsch" test characteristic octahedral and tetrahedral crystalline sublimates were obtained of arsenic tri-oxide evidently (since selenium does not give the characteristic crystalline sublimate). By the "Marsh" test in no case were the curious characteristic mirrors obtained, such as are given by selenium with small amounts of arsenic (Experiments 1 and 2 , Figs. 1 and 2). Hence $I$ think that these facts conclusively prove that the poisoning could not have been due to selenium primarily and arsenic secondarily, as has been suggested, for the mirrors obtained by the "Marsh" test on the contaminated samples would have at once demanded attention by their most remarkable appearance.

St. Mary's Hospital, W.

\section{SEPTIC DISEASE IN GRADUATED ATTACKS IN THE SAME PATIENT.}

\section{BY J. SNOWMAN, M.D. BRUX., M.R.C.S. ENG., L.R.C.P. LOND.}

THE following case affords an interesting stúdy of variations in the development of the same disease in the same individual at different times but under similar predisposing circumstances. The facts concern a healthy female who was 34 years of age when her present history began five years ago. She was then lying-in with her sixth child and had three or four severe rigors between the third and sixth days. As these rigors, in which the temperature rose to $105^{\circ} \mathrm{F}$., were not accompanied by any untoward abdominal or uterine symptoms, and as convalescence was established normally, the condition was regarded as one of those vague cases of puerperal pyrexia of uncertain origin. These cases, which have been variously attributed to milk fever or nervous disturbance, are now considered by the best authorities to be septic in nature and are to be interpreted pathologically as the successful resistance of the healthy organism against an attack of the micrococci of septicrmia.

The patient became pregnant again towards the middle of January, 1898. After seven weeks' amenorrhcea she aborted. The abortion was attended by severe hæmorrhage so that no traces of the embryo were to be detected in the portions of the ovum which were expelled piecemeal. When the patient was first seen the uterus could be felt midway between the pubes and umbilicus; it was soft and compressible and evidently filled with blood-clot. The temperature was $102^{\circ}$ and the cervix admitted one finger, but the internal os was closed. The blood contained in the uterus was expressed and its cavity irrigated with Condy's fluid. For two days all went well, but on the third day the patient had a rigor, with a temperature of $104^{\circ}$; there were abdominal pains, but no real tenderness was present. The rigor was followed by profuse sweating. The external os still admitted one finger, and the uterus was enlarged, its contents being chocolate coloured. Irrigation of the uterus was continued. The temperature became normal during the day, but on the following evening there was another rigor and the temperature rose to $105^{\circ}$. The uterus was then thoroughly explored with the finger, counter pressure being made over the hypogastrium. By this manceuvre a few shreds were removed. The next few days were uneventful, but bruises gradually appeared on the hypogastrium where the fingers had exerted pressure and on the vulva from the pressure of the thumb of the examining hand. The temperature rose to $103^{\circ}$ and these bruises, four in number, became large inflammatory indurated swellings. The uterine condition was now quite healthy, but three of these local swellings suppurated and required free incisions to give vent to the pus. After 
this the temperature gradually fell and the patient soon recovered.

These facts may be interpreted to mean that the patient was threatened with septicæmia in this abortion, as she had been in her previous confinement. It may be tbat her tissue resistance would again bave repelled the attack of the streptococci ; it may be that the digital curetting of the uterus after the second rigor saved the situation. In any case the micro-organisms of suppuration were in the blood producing a toxæmia, but instead of proceeding to a general pyæmia they spent themselves in the loci resistentice minoris afforded by the bruised areas of the hypogastrium and vulva, and there their specific action was exerted.

The next pregnancy of the patient also terminated abruptly in an abortion, but unfortunately the septicæmia with which it was again attended did not abort. The patient's last menstrual period ended at the beginning of September, 1899. She then had amenorrhœea for five weeks, when a sanious discharge made its appzarance and lasted for three weeks, culminating in the expulsion of a clot on Nov. 5th. On that day the patient experienced a severe rigor. On making a vaginal examination the following day it was found that the cervical canal was open and the uterus distended to the size of a three months pregnancy. The temperature was then $101^{\circ}$, but that night there was another rigor. At 6 A.M. on - Nov. 7th a complete abortion took place, the ovum being expelled entire, and it was a perfect specimen of six and a balf weeks' growth. The temperature was then $99^{\circ}$. On Nov. 8th there was another rigor; the following morning the temperature was $102^{\circ}$, there was slight cedema of both legs, some fulness in the ankles and knees, with tenderness on deep pressure. There was also pain in the right shoulderjoint severe enough to prevent movement. The temperature fell to $99^{\circ}$ the next day, but rose gradually to $104^{\circ}$ in the afternoon, while the pain and swelling in the left ankle and knee increased. The condition of the left knee became much worse and assumed the appearance of very acute osteo-arthritis; the temperature rose to $1052^{\circ}$. For the next few days it fluctuated between $101.5^{\circ}$ and $104^{\circ}$, but the swelling of the knee and ankle decreased somewhat, so that free passive movement was possible in the latter joint. Some erythema which had been present over the ankle disappeared com. pletely. The circumference of the left thigh just below the apex of Scarpa's triangle was two inches greater than that of the right in the corresponding position. But with the indications of apparent subsidence of the mischief in the lower limb redness and effusion began to appear over the right wrist, marking out at first the synovial sheath superficial to the joint. This condition increased and the welldefined redness gave way to an odematous surface of a purple hue. With this a similar patch, possessing all the physical characters of erysipelas, began to appear over the left olecranon. The elbow-joint was not involved. While the swelling over the right wrist was becoming fainter and less dusky the cutaneous intlammation over the elbow was spreading. Meanwhile the left ankle became quite free in its movements, though cedema of the foot persisted; there was still pain on attempting to extend the knee from its flexed position, though it could with difficulty be straightened out. Neither at this time nor at any time during the whole conrse of the illness was there any uterine trouble. That organ was freely moveable and there was no induration in the pelvic cellular tissue. During the next few days the erysipelatous patch over the left elbow crept up as far as the shoulder and half-way down the forearm; then it began to subside gradually, leaving the limb considerably increased in size. The effusion over the right wrist still persisted and it became obvious from the general condition and the temperature chart that the swelling had suppurated. On Nov. 27th the swelling was opened under A.C.E., and about two ounces of thick curdy pus were evacuated, hot fomentations being subsequently applied. For the next few days there was favourable progress, the incision was healing well. and the temperature kept below $101^{\circ} \mathrm{F}$. Then the leg began to be extremely painful and the cedema increased. Occasionally the pain was agonisingneither active nor passive movement was possible. At this time there were decided bogginess and distension of veins over the posterior surface of the left elbow and pain in one definite spot on the olecranon process. In the interval between the olecranon and external condyle there was a distinct sense of fluctuation and there appeared to be inflammatory exudation from this area extenciing lower down the limb, but the movements of the joint were quite free. The general state of the patient pointed to more pus in the body and the physical signs of the elbow region seemed to localise it there. But an incision down to the bone in the oedematous area failed to reveal any purulent collection. As the patient was under an anæsthetic the knee-joint was explored by means of a syringe but only ciear fluid was drawn off. The syringe was ggain inserted into the odematous thigh, in the lower and outer third, and on this occasion some purulent fluid was removed. The puncture was enlarged by an incision one and a half inches long and about three-quarters of a pint of dark sanious pus escaped. A counter opening was made towards the posterior surface of the limb and a large drainagetube was inserted. This operation was performed on Dec. 14th and from this time matters improved considerably, but only for a few days. It became obvious that the drainage was imperfect and that the abscess cavity was bagging. The temperature rose again to $103^{\circ}$, the pain in the knee increased, and the discharge practically ceased. On Dec. 28th the patient was again anæsthetised and the knee explored with a syringe; there was no pus and but very little clear fluid. On pushing a long probe downwards from the lower incision on the outer side of the thigh it was found to penetrate the joint, and its end could be felt projecting at the inner side of the knee. Through the original incision in the thigh about two inches of bare temur could be felt. This incision was extended downwards and a counter incision was made on the back of the limb, a drainage tube being passed right through. Another incision was made along the course of the probe inserted in the limb. A further incision was made into the knee-joint from the outer side and it was found that adbesions were forming between the articular cartilages. This incision was stuffed with iodoform gauze and the limb fixed on an interrupted back splint. The drainage was now free, and after a couple of days the temperature fell to normal, and with one or two occasional elevations to $100^{\circ}$ remained so permanently. Pus discharged in small quantities from the incisions for about three we ks, and when the tubes were completely removed the wounds healed absolutely well without leaving sinuses. A poroplastic felt splint was fitted to the knee and the patient was encouraged to sit up in bed. Massage and passive movements were begun. Convalescence was very tardy owing to cedema of the leg and foot, with a markedly cyanotic conditicn of the latter. On March 9th, 1900, the patient sat up out of bed for the first time, and from this date improvement was steady, so that now she is in perfect health with the exception of some ankylosis of the knee.

The foregoing is, of course, the histor $y$ of a typical attack of pyæmia ending in recovery and forms the climax of the gradual series of septic disease from which the patient has suffered. The interest of the case is certainly considerable, and looked at from the point of view of its relation with the preceding attacks, similar in nature but different in degree, gains in importance. It is perfectly clear that this patient possesses the power of elaborating from her own tissues an antitoxin which is inimical to the growth of the streptococci of suppuration. Their first invasion was met by an immediate production of antitoxin and the only indications of a struggle were the pyrexia and rigors. On the second occasion the mobilisation of the chemical forces of the body was less rapid, there were weak spots in the defencei.e., the bruises of the impressed finger-marks-and here local suppuration occurred. But still the general preparations of tissue resistance proved to be good and a pjæmia was warded off. On the third occasion, however, eitber from the intensity of the attacking poison or delay in the elaboration of the defensive antitoxin, the resistance was slow and there was time for true embolic or pyæmic processes to take place before success was achieved.

The entrance of the cocci must obviously have been through the genital tract, and in the last illr ess was not the result of contagion in the ordinary sense, as the first rigor occurred before any vaginal examination had been made. The case demonstrates that the seat of inoculation may entirely escape the local processes of the disease, and this is a point which should be remembered in makirg a diagnosis when puerperal pyrexia is not attended by inflammation of the pelvic cellular tissue, peritoneum, or uterine appendages. Incidentally some light is shed on the pathology of erysipelas, for the occurrence of absolutely typical patches of this condition warrants us in discarding the timehonoured doctrine that this disease must be preceded by a breach of surface to serve as the site of inoculation. 
Erichsen records a case of pyæmia in which a collection of pus was found in the intermuscular strata of the lower third of the thigh. There was a free communication between the abscess cavity and the knee-joint and the author concludes that the joint had supparated and its contents extravasated into the tissues of the limb. In the present case 10 will be remembered that the probe inserted into the abscess cavity passed right down into the joint. In dressing the limb it was seen that all the pus came from below opwards, and when drainage was deficient pus could only be ontained on making pressure in that direction. Assuming that in the present instance the joint suppurated and that the pus found its way into the tissues of the thigh the subsidence of the effusion in the knee and the increased circumference of the limb are easily explained.

It is impurtant to note that this case narrowly escaped record as an example of cure by anti-streptococcic serum. About the fourteenth day of the disease, when its septic nature had long become obvious and the condition of the patient was exceedingly grape, the temperature remaining between $102^{\circ}$ and $104^{\circ}$, it was determined to use this serum, and preparations were actually made for this purpose. At the very last moment, however, in view of the fact that so far tbere had been no actual evidence that it was a pus-producing organism which was at work, the injection was abındoned. The very next morning the temperature had fallen from $104^{\circ}$ to $99^{\circ}$. If the injection had been administered it would have been held responsible for this sudden dro $\rho$ and would donbtless have been regarded as having influenced favourably the whole course of the disease. The treatment of the case on ordinary surgical lines shows that it was not any antitoxin artificially injected into the tissues which determined recovery, but the actual production of the antitoxin from the constituents of the blood of the patient.

Spitalfields, $\mathbf{E}$.

\section{Clinital :}

\section{MEDICAL; SURGICAL, OBSTETRICAL, AND THERAPEUTICAL.}

\author{
PAROTITIS AFTER ABDOMINAL SEOTION. \\ By Bertram ADDENBrooke, M.D. DURH., M.R.C.S. \\ ENG, \&O.
}

IN The Lancet of Jan 19th, 1901, p. 176, Dr. William Elder records a case of parotitis atter abdominal section, a brother of the patient who was living in the same house having had an attack of parotitis epidemica (mumps) 49 days previously. This, considered in contrast with cases under my care where two cases occurred in other members of the family after parotitis in a patient, a sequel to abdominal section, ${ }^{1}$ is, as Dr. Elder remarks, very interesting, and although he is of opinion that it is doubtful whether his case was one of parotitis (from metastasis?) or true mumps, I venture to think that the previous occurrence of parotitis epidemica in the house was only a coincidence. There is, however, one very striking point of resemblance between the cases reported by Dr. Elder and by myself. It is this: three days after the operation on his patient parotitis developed, and as I recorded in THE LANCET of Dec. 29th, 1900, there was the same duration of time in the case under my care and, furthermore, in the two other members of the family who subsequently suffered from parotitis there was the same interval between the exposure to infection and the supervention of parotitis as in the abdominal cases -namely, three days.

Kidderminster.

\section{DORSAL DISLOCATION OF THE FIRST PHALANX OF} THE LITTLE FINGER.

By Edwyn M. RIDGE, M.R.O.S. ENG., L.R.O.P. Lond.

Having seen the artisle on Dorsal Dislocation of the First Phalanx of the Little Finger by Mr. Harold L. Barnard in The LANCET of Jan. 12tb, 1901, p. 88, I think it would be interesting to record a case of what he calls a "complete complex dislocation" which came under my notice shortly afterwards. A youth, aged 19 years, came into the receiving-room of the Poplar Hospital for Accidents where repeated attempts were made at reduction by the ordinary methods. He gave a history of falling backwards and in putting out his hand behind him to save himself he bent his finger backwards. Further attempts were made under an anæsthetic without avail, and then the simple operation suggested by Mr. Barnard was resorted to with very favourable result, the patient making an uneventful recovery, good movement and power being already attained. The way in which the accident occurred in the case which I have described seems to me much more likely to happen frequently than that which Mr. Barnard alleges.

Enfield.

\section{SERUM TREATMENT OF DIPHTHERIA ON THE} FOURTH DAY OF THE DISEASE.

By Ralph S. McD. Pullen, M.R.O.S. Eng., L.R.C.P. LOND.

ON a Wednesday evening recently, at 11 P.M., I was sent for to see a child, aged four years, who was stated to be suffering from a "sore-throat." The patient had been taken ill on the previous Sunday. I found the tonsils covered with membrane and bleeding. There was a nasal discharge. Such difficulty of breathing as existed was due to nasal and not to laryngeal obstruction. The temperature was below $100^{\circ} \mathrm{F}$. At midnight I administered an injection of serum under the skin of the abdomen. The patient was comfortable and slept during the night and in the morning appeared somewhat brighter as regarded her general condition. I advised her removal to hospital where she received a second injection at 1 P.M. on the Thursday. The membrane disappeared with marvellous rapidity and the general improvement was very marked. She has made a good recovery up to the present time.

I communicate this case as I consider the interest lies in the successful issue of an injection $a^{t_{i}}$ such a late periodsome 96 hours - after the invasion of the disease.

Stoke, Devonport.

\section{A êtirnor}

\section{H OS PITAL PRACTICE, B RITISH AND FOREIGN.}

Nulla autem est alia pro certo noscendi via, nisi quamplurimas et morborum et dissectionum historias, tum aliorum tum proprias collectas habere, et inter se comparare.-MoRGaGNI De Sed. et Caus. Morb., lib. iv., Proœmium.

\section{WESTMINSTER HOSPITAL.}

A CASE OF HECURRENT APPENDICITIS COMPLICATED BY GENLRAL SEROUS PERITONITIS AND EFFUSION.

(Under the care of Mr. W. G. SPENCER.)

Pronably the rarest complication of inflammation of the appendix is a serous-i.e., non-purulent-effusion and this is due to the fact that if an appendicitis is sufficiently severe to cause any peritonitis this will be due to the passage of micro-organisms through the wall of the appendix, and these micro-organisms are nearly always pyogenic. If, however, merely toxins pass into the peritoneum or microbes of a mild type then a non-purulent peritonitis may arise which may disappear after drainage. It would have been of interest to have had the result of a bacteriological examination of the peritoneal fluid in the following case, and an examination of the sputum in the pneumonia might have shown an identity in microbic infection between the peritonitis and the pneumonia. For the notes of the case we are indebted to $\mathrm{Mr}$. A. Whitehouse, dresser.

A well-nourished generally bealtby man, aged 24 years, was admitted into Westmirster H sspital on Dec. $29 \mathrm{tb}$, 1900 ; there had been severe pain in the abdomen and repeated vomiting for the previous 24 hours $\mathrm{He}$ had had a right inguinal hernia optrated on by Mr. W. Anderson at St. Thomas's Hospital. In November last the patient had been suddenly 